\title{
Health-related quality of life and metabolic risk in patients with psychosis
}

\author{
Anniqa Foldemo, Rikard Wärdig, Margareta Bachrach-Lindstrom, Gunnar Edman, Tommy \\ Holmberg, Torbjörn Lindström, Lars Valter and Urban Osby
}

\section{Linköping University Post Print}

\section{Tweet}

N.B.: When citing this work, cite the original article.

Original Publication:

Anniqa Foldemo, Rikard Wärdig, Margareta Bachrach-Lindstrom, Gunnar Edman, Tommy Holmberg, Torbjörn Lindström, Lars Valter and Urban Osby, Health-related quality of life and metabolic risk in patients with psychosis, 2014, Schizophrenia Research, (152), 1, 295299.

http://dx.doi.org/10.1016/j.schres.2013.11.029

Copyright: Elsevier http://www.elsevier.com/

Postprint available at: Linköping University Electronic Press http://urn.kb.se/resolve?urn=urn:nbn:se:liu:diva-104125 


\section{Health-related quality of life and metabolic risk in patients with psychosis}

Anniqa Foldemo, $\mathrm{PhD}^{1,5}$, Rikard Wärdig $\mathrm{MScN}^{1}$, Margareta Bachrach-Lindström, $\mathrm{PhD}^{1}$, Gunnar Edman $\mathrm{PhD}^{2,3}$, Tommy Holmberg $\mathrm{MScPh}^{5}$, Torbjörn Lindström, $\mathrm{PhD}^{1}$, Lars Valter $\mathrm{MSc}^{5}$, Urban Ösby $\mathrm{PhD}^{2-4}$

1. Department of Medical and Health Sciences, Linköping University, Sweden.

2. Department of Molecular Medicine and Surgery, Neurogenetics, Karolinska Institutet, Stockholm, Sweden.

3. Center for Molecular Medicine, Karolinska Institutet, Stockholm, Sweden.

4. Department of Psychiatry, Tiohundra AB, Norrtälje, Sweden.

5. R\&D Department, County Council of Östergötland, Linköping, Sweden.

Corresponding author: Anniqa Foldemo

Department of Medical and Health Sciences, Linköping University, Sweden

SE-581 83 Linköping,

Sweden

Tel+4613285891

Email: anniqa.foldemo@liu.se 


\begin{abstract}
Improved Health-related quality of life (HRQoL) is an alternative treatment goal for individuals with psychosis, who have up to two times greater prevalence of type 2 diabetes, hypertension and obesity than the general population. Aim: to compare HRQoL in patients with psychosis, especially schizophrenia, with a reference sample and explore the relationship between HRQoL and metabolic risk factors in these patients. Methods: a prospective cohort study was carried out in specialized psychiatric outpatient departments in Sweden. The patients were invited consecutively. A prospective population-based study of public health in the south-east of Sweden served as reference group. Patients were assessed with psychiatric questionnaires that included Global Assessment of Functioning (GAF). Health-related quality of life was assessed using the questionnaire EQ5D, both for patients and the population, and several other health status outcomes were used. Results: At 73\%, schizophrenia and schizoaffective disorder were the most common diagnoses in the patient group. The results in patients $(n=903)$ and population $(n=7238)$ showed significant differences in lower EQ5D among patients. According to the definition by the International Diabetes Federation (IDF), elevated blood pressure was the only metabolic risk associated with lower HRQoL in patients. Raised LDL-cholesterol levels were also significantly related to lower HRQoL. Conclusion: patients suffering from psychosis had significantly lower HRQoL regarding all components in EQ5D, except for the pain/discomfort component. Almost half of the patient group met the criteria for metabolic syndrome. According to the IDF criteria, elevated blood pressure was the only metabolic risk factor that had an impact on HRQoL.
\end{abstract}

\title{
Keywords:
}

Metabolic syndrome, schizophrenia, health-related quality of life, reference group. 


\section{Introduction}

Since most patients with long-term psychotic disorders, including schizophrenia, have a lifelong disorder, improved health-related quality of Life (HRQoL) is an important treatment goal (Resnick et al., 2005). HRQoL encompasses several important dimensions including psychological status, functional abilities, personal well-being and physical health (Cramer et al., 2000). A number of factors have been studied in relation to HRQoL in psychiatric patients. Lower everyday functioning, greater severity of symptoms and higher education level have been associated with lower QoL (Ruggeri et al., 2005; Skantze, 1998). Increasing age, however, has been associated with higher HRQoL (Caron et al., 2005).

The generic health-related quality of life assessment instrument EQ5D has been used in population surveys in many countries (Burstrom et al., 2001; Kind et al., 1998), and has also been proved valid in patients with schizophrenia (Bobes et al., 2005; Konig et al., 2007). The EQ5D generates a health profile together with a single index score for HRQoL (Konig et al., 2007) and can detect differences in quality of life among patients with different disease severity (Bobes et al., 2005).

Various diagnostic criteria for metabolic syndrome have been proposed by different organizations over the past few years. The diagnostic criteria according to IDF (2009) include elevated waist circumference, triglycerides, blood pressure and fasting glucose together with reduced HDL-cholesterol (Alberti et al., 2009). Metabolic risk factors seem to be related to HRQoL. Studies of patients with psychotic disorders describe a strong correlation between obesity and lower subjective HRQoL (Faulkner et al., 2007; Strassnig et al., 2003).

Patients with schizophrenia have a 15-20 percent shorter life expectancy than the general population (Crump et al., 2013; Marder et al., 2004). The main explanation is linked to the consequences of metabolic risk factors and subsequent development of cardiovascular diseases (Crump et al., 2013; Laursen et al., 2012). Individuals with psychosis have up to two time's higher prevalence of type 2 diabetes, hypertension and obesity than the general population (McEvoy et al., 2010; Newcomer, 2005).

Previous research shows an association between prevalence of different risk factors for metabolic syndrome and lower HRQoL in patients with depression and anxiety (Roohafza et al., 2012). Both men and women with metabolic syndrome had lower HRQoL compared with 
controls without the metabolic syndrome in a non-disease specific population study (Frisman and Kristenson, 2009). It is therefore important to study the influence of metabolic risk factors also in patients with psychotic disorders due to the increased risk of influence on HRQoL and the association with high morbidity.

The aim of this study was to compare HRQoL in patients with psychosis, especially schizophrenia, with a reference sample and to analyze the relationship between HRQoL and metabolic risk factors in these patients.

\section{Methods}

\section{2:1 Patients}

A sample of 903 patients was included. The patients, aged over 18, were consecutively invited to participate in the study when visiting specialized psychiatric outpatient departments for patients with long-term psychotic disorders in the County of Stockholm and six other locations in Sweden between 2005 and 2012. They were diagnosed with schizophrenia or other long-term psychotic disorders (ICD10). Seventy-three percent were diagnosed with schizophrenia or schizoaffective syndrome, 21 percent with other forms of psychosis, and 6 percent with bipolar disorder (Table 2).

Patients were assessed regarding level of functioning, using the Global Assessment of functioning (GAF) (American Psychiatric Association (1994) Diagnostic and Statistical Manual of Mental Disorders (DSM-IV), American Psychiatric Press, Washington D.C), duration of illness and duration of treatment. Patient severity was assessed with the Clinical Global Impression (CGI) scale (National Institute of Mental Health (1970) 12-CGI. Clinical Global Impressions. (In: Guy W, Bonato RR (eds) Manual for the ECDEU Assessment Battery, vol 2. Chevy Chase, Maryland, pp 12:11-16)(Guy et al., 1970).

Somatic health was assessed with an own developed questionnaire about cardiovascular disease, diabetes and hypertension. Data on patients' current medication for these conditions were collected. The questionnaire also included questions on smoking habits and alcohol consumption. We have only presented data on alcohol consumption and smoking habits in this article. Blood pressure was taken in the supine position. Weight was measured with a calibrated weight scale. Body height and weight, as well as waist circumference were 
measured, and BMI was calculated. Blood samples were drawn with the subjects fasting and subsequently analyzed using routine methods at the Karolinska University Hospital laboratory. The laboratory was accredited according to a quality assurance system (Good Laboratory Practice; GLP).

Health-related quality of life was assessed using the EQ5D questionnaire, a standardized instrument for measuring health status (Dolan, 1997). The EQ5D questionnaire includes five items related to mobility, self-care, usual activities, pain/discomfort and anxiety/depression. Responses in each dimension are divided into three ordinal scales: 1) no problems, 2) moderate problems, and 3) extreme problems. The EQ5D scores were converted into a single summary EQ5D index, which quantifies health status (Brooks, 1996). The index has a range of -0.594, (lowest HRQoL), to 1.000, (highest HRQoL) and 243 possible health outcomes.

\subsection{Reference group}

A population-based survey sample served as reference group. The survey was conducted in 2006 and included individuals from the general population aged 18 to 84 years. The survey was stratified with respect to age, gender and community, with a total sample size of 13,440 . The reference group was assessed with a self-administrated questionnaire, which included somatic health as well as smoking and alcohol habits. The questionnaire also included selfreported weight, height and EQ5D assessment.

The reference group had a 54 percent response rate $(n=7,238)$. The response rate was lowest among males aged 18-29 years (32\%) and highest among both males and females aged 45-64 years $(60 \%)$ and $65-89$ years $(69 \%)$.

\subsection{Statistical analysis}

All statistical analyses were performed with SPSS 20.0. The distribution of alcohol consumption was severely skewed with 19.3 percent consuming no alcohol in the reference sample and 41.2 percent in the patient group. Thus, comparisons between the groups were performed on stratified data ( $0 \mathrm{~g}$ alcohol per week/non-consumers, 1-199 g /moderate consumers, and >199 g/ high consumers). All variables were summarized with standard descriptive statistics, e.g. mean and frequency. Differences between the reference sample and the patients regarding gender and smoking were analyzed with Pearson's $\chi$-test. Differences in age, alcohol consumption and EQ5D index were analyzed with two-way (group*gender) 
analysis of variance (ANOVA), since there was a significant difference in the gender distribution (cf. below).

The relationship between HRQoL and BMI was analyzed in a three-way ANOVA (group*gender*BMI-group) with age as a covariate, in which the relationship between the separate factors (group, gender and BMI-group) and the EQ5D index appeared as main effects.

The relationship in HRQoL according to the EQ5D index and the metabolic risk factors was analyzed with a logistic regression analysis (stepwise forward with an inclusion criterion of 0.050). In the analysis, the index was dichotomized according to the median (0.80 vs. >0.80) and used as the dependent or "outcome" variable. All variables constituting the metabolic syndrome (www.idf.org/webdata/docs/MetS_def_update2006.pdf), including the metabolic syndrome per se were entered as independent variables together with gender (gender is female), age (>45 years/Md value), smoking (current), high LDL-cholesterol (>3.4 mmol/L or lipid-decreasing medication) and GAF ( $>50)$ all of them coded ( $0=$ "No" and 1= "Yes").

\subsection{Ethics}

The procedures were in accordance with the ethical standards of the local ethic review committee and the Declaration of Helsinki of 1964, revised 2008. The protocol was approved by the Regional Ethics Committee at Linköping University (dnr 2004-447/4, 2008/1629-32) All patients gave their informed consent.

\section{Results}

\subsection{Demographic and clinical characteristics}

There was a significantly higher proportion of men in the patient group compared to the reference sample $\left(\chi^{2}=33.32, p<0.001\right)$. The mean age of the reference sample was 4 years older than that of the patients, but when split according to gender, the age difference was limited to men ( $M=52.9$ vs. $M=45.1$ for men, and $M=49.8$ vs. $M=49.1$ for women). The interaction effect was thus highly significant $[\mathrm{F}(1,8,320)=35.49, \mathrm{p}<0.001]$. Demographics are presented in Table 1. Age was entered as a covariate in all of the ANOVAs. 
GAF was 61 or below in $80 \%$ of the patients. CGI was 4 and over, i.e. moderately or severely ill, in 50 percent of the patients.

Of the patients, 44.4 percent of the men and 39.5 percent of the women were smokers, compared to 18.2 and 20.5 percent, respectively, in the reference group $\left(\chi^{2}=172.30 ; p<0.001\right.$ for men and $\chi^{2}=76.92 ; \mathrm{p}<0.001$ for women).

Approximately 40 percent of the male and 42.5 percent of the female patients with psychotic disorder were non-consumers of alcohol compared to 14.1 of the men $\left(\chi^{2}=202.19 ; p<0.001\right)$ and 23.7 percent of the women $\left(\chi^{2}=68.32 ; \mathrm{p}<0.001\right)$, respectively, in the reference sample. Among the patients, 15.4 percent of the men were high consumers of alcohol (>199 g/week) compared to 4.0 of the men in the reference sample $\left(\chi^{2}=105.56 ; \mathrm{p}<0.001\right)$, and 7.5 percent of the female patients compared to 1.3 percent of the women in the reference sample $\left(\chi^{2}=77.29\right.$; $\mathrm{p}<0.001)$.

The difference, corrected for age, between the patients and the reference sample in BMI was highly significant $[\mathrm{F}(1,7,744)=469.61, \mathrm{p}<0.001]$, with a higher BMI among patients $(28.9$ vs. $\left.25.5 \mathrm{~kg} / \mathrm{m}^{2}\right)$. The difference was somewhat greater for women $\left(29.3 \mathrm{vs} .25 .1 \mathrm{~kg} / \mathrm{m}^{2}\right)$ than for men $\left(28.7\right.$ vs. $\left.26.0 \mathrm{~kg} / \mathrm{m}^{2}\right)[\mathrm{F}(1,7,744)=13.17, \mathrm{p}<0.001]$.

\subsection{HRQoL in patients and reference sample}

Patients had significantly lower ratings of EQ5D index than the reference sample [F (1, $7,979)=128.21, \mathrm{p}<0.001]($ Table 1$)$. There was no significant interaction with gender $[\mathrm{F}(1$, $7,979)<1.00, p=0.371]$. In univariate analysis there was a significant association between EQ5D index and GAF but the correlation was rather weak $(r=0.17 ; \mathrm{p}<0.01)$.

Specific EQ5D ratings were also analyzed with significant differences in mobility $[F(1,8,058)=23.91, \mathrm{p}<0.001]$, hygiene $[\mathrm{F}(1,8,061)=22.77, \mathrm{p}<0.001]$, main activities $[\mathrm{F}(1,8,062)=266.06, \mathrm{p}<0.001]$, pain/discomfort $[\mathrm{F}(1,8,049)=4.33, \mathrm{p}=0.037]$, and worry/sadness $[\mathrm{F}(1,8,058)=400,37, \mathrm{p}<0.001]$. The patients had lower ratings, i.e. worse health-related quality of life, than the reference group in all comparisons, except for the pain/discomfort rating where the reference group was somewhat lower $(\mathrm{p}=0.037)$. 
Taking gender into consideration, the difference in mobility was limited to women, with female patients having more problems $(20.2 \%)$ than the females in the reference group $\left(15.3 \% ; \chi^{2}=6.52, p=0.011\right)$. Furthermore, male patients had more problems with main activities than males in the reference group $\left(29.6 \%\right.$ vs $\left.7.8 \% ; \chi^{2}=215.64, \mathrm{p}<0.101\right)$, although the difference was also significant for women $(26.8 \%)$ vs. $\left.11.9 \% ; \chi^{2}=71.53, \mathrm{p}<0.001\right)$.

The difference in problems with mobility was limited to the younger group ( $<44$ years), with 11.3 percent in patients and 3.5 percent in the reference sample $\left(\chi^{2}=50.92, p<0.001\right)$. Furthermore, pain/discomfort was greater in the older group with 48.9 percent in the patient group and 66.3 percent in the reference sample $\left(\chi^{2}=67.03, \mathrm{p}<0.001\right)$.

\subsection{Relationship between HRQoL and BMI in patients and reference sample}

There was a significant relationship between BMI and $\operatorname{HRQoL}[F(3,7,617)=15.30$, $\mathrm{p}<0.001]$, with the lowest EQ5D index in the group with the highest BMI (>35) and the highest index in the group with the lowest BMI $(<26)$. There were no significant differences between the two lowest groups ( $<26$ vs $26-30)$.

\subsection{Relationship between HRQoL and metabolic risk factors in patients}

Within the patient sample, 46 percent fulfilled the criteria for the metabolic syndrome according to IDF(2009). Among the factors defining the syndrome, waist circumference was most increased, (63 percent), followed by fasting glucose (61 percent), and blood pressure (59 percent) (table 2). Low GAF score, increased LDL-cholesterol levels and increased blood pressure were associated with lower HRQoL as well as being older than 44 years (table 3 ).

Eleven variables were entered as independent variables in the logistic regression analysis: gender, age (18-44 vs. 45- years), smoking, LDL-cholesterol, global level of functioning (GAF), CGI, and the metabolic risk factors that define the metabolic syndrome (elevated waist circumference, triglycerides, blood pressure and fasting glucose together with reduced HDL cholesterol)(Alberti et al., 2009). Six variables, lower GAF, lower CGI, higher blood pressure, higher LDL cholesterol levels, age 45+ and female gender, were significantly and independently related to a lower EQ5D index (Table 3).

\section{Discussion}

\section{Main findings}


The main finding of this study was that patients suffering from psychosis had significantly lower health-related quality of life compared to a population-based reference group. Among the patients, somewhat surprisingly, only one of the metabolic risk factors in the metabolic syndrome according to the IDF definition (2009), elevated blood pressure, was associated with lower HRQoL. Another metabolic risk factor, not included in the metabolic syndrome, raised LDL-cholesterol, was also associated with lower HRQoL among the patients.

\section{Strength and limitations}

Our study was a large cohort study that took place at a number of sites in Sweden. It was a unique opportunity to compare the patient cohort with a large population-based sample. Since the study was cross-sectional, it was not possible to extract any conclusive causal relationships. The low attrition rate in the population study was problematic. However, within the most common age group (40-60 years), the attrition rate was equal to the patient group. There was also a difference between patients and the general population concerning the administration of the questionnaires. Patients' self-administrated questionnaires were completed at the clinic whereas those of the population were sent out by mail and completed at home. This difference could have caused bias not only in the population-based sample, but also in the patient cohort. Patients may have felt uncomfortable answering the questionnaire reliably in the presence of staff. On the other hand, due to the anonymity of population-based studies, there is always a risk of false response. It would also have been useful and a strength to take the patients antipsychotics into consideration. However, we did not have access to valid data on type of medical treatment.

\section{Comparisons with other studies}

Low HRQoL in patients with schizophrenia has been previously reported (Ritsner et al., 2000). Obesity is generally found to be associated with lowered HRQoL in both healthy individuals and in different patient groups but no such association was found in this study when assessed with obesity measured as waist circumference, while there was an association with BMI. Waist circumference is a part of the metabolic syndrome and is considered to give a better measure of visceral fat than BMI (Despres et al., 2008).

Increased LDL-cholesterol, which is a strong risk factor for cardiovascular disease but not related to insulin resistance and not included in the metabolic syndrome, was associated with lower HRQoL in patients. This association has not, to our knowledge, been reported 
previously in patients with psychosis. As this is a cross-sectional study, no causal relationship can be established, higher levels might be both a reason for and an effect of low HRQoL and the mechanisms remain to be further analyzed. A reason for high LDL-cholesterol levels in these patients might be that an unhealthy lifestyle with a possible high intake of saturated fat and carbohydrates is common (Dipasquale et al., 2013), and that physical activity levels are low. There is also a positive association between levels of LDL-cholesterol and obesity (Klop et al., 2013). A large proportion of our patients had high BMI. We also found a negative association between high blood pressure and HRQoL. Such an association has previously been found in the general population with hypertension, although the difference compared with normotensive individuals is rather small (Trevisol et al., 2011). From a clinical perspective, treatment of hypertension seems important as good blood pressure control can improve HRQoL (Zygmuntowicz et al., 2013).

Other variables significantly related to lower HRQoL among patients were low GAF, older age and female gender. Such associations have been described previously (Caron et al. 2005, Carpiniello et al. 2012. The function is assessed in two different ways in GAF and HRQoL, which can be viewed as strength. GAF is assessed by the clinician whereas function in EQ5D is self-reported. Although significant the association between them was rather weak implying that they measure partly different aspects. In all comparisons of the specific components of EQ5D, the patients had lower HRQoL ratings than the reference group, except for the pain/discomfort rating where the reference group had somewhat lower HRQoL. Most problems in the dimension pain/discomfort in a population group have been reported in an earlier study (Burstrom et al., 2001).

Significant proportions of patients with psychosis have developed, or are at risk of developing metabolic syndrome (Meyer and Stahl, 2009). In our study, 46 percent of the patients met the criteria for metabolic syndrome according to the IDF (2009) definition. These high numbers can be related to frequent unhealthy lifestyle choices (Foley and Morley, 2011), which combined create problematic prerequisites for health and HRQoL.

A comparison between the two groups showed that high BMI and extensive consumption of alcohol were significantly higher in patients than in the reference group. High BMI in patients with schizophrenia is well-known (Fountoulakis et al., 2010; McEvoy et al., 2010), 
and is associated with reduced HRQoL(Renzaho et al., 2010). A study by Strassnig and colleagues (2003) showed reduced HRQoL in both patients with schizophrenia and in controls with high BMI (Strassnig et al., 2003). These results are in line with our study, which also shows the impact of BMI on HRQoL both in patients and the reference group.

Smoking is another risk factor, and in the present study there was a significantly higher proportion of smokers among the patients compared to the reference sample. This high rate of smoking is in line with findings in another study and smoking is obviously an important risk factor for cardiovascular disease (Bobes et al., 2010). A Swedish study of lifestyle habits in psychosis within a clinical setting found that $30 \%$ of patients were abstainers and $49 \%$ were smokers (Cruce and Ojehagen, 2007). The number of smokers was similar in our study but there were fewer abstainers.

Several studies show that smokers in general have other concurrent problematic lifestyle habits. They drink more alcohol, have lower levels of physical activity, eat less fruit and vegetables and have lower HRQoL (de Miguel Diez et al., 2010; Strine et al., 2005). The alcohol consumption pattern found among patients in our study, in comparison with the reference group, shows that the majority are either high consumers or non-consumers. These self-reported values can certainly be questioned. This is because health care recommends sobriety when taking antipsychotic medication. This raises the question if the patients' responses are influenced by the care recommendations. At the same time, we know that alcohol has an anti-anxiety effect, at least in the short term, which could explain the high proportion of high consumers.

In line with our study, female gender (Carpiniello et al., 2012) and older age were associated with lower HRQoL (Caron et al., 2005). On the contrary, another study did not find any gender differences in HRQoL (Heider et al., 2007). Older age might lead to worse living conditions (Mercier et al., 1998).

The result of the study shows the need for monitoring physical health and development of intervention programs suitable for this patient group in order to both reduce risk and improve long-term physical health and quality of life. This can be a major challenge as this group may have difficulty maintaining an interest in participating in health interventions (Hultsjo, 2012; Scott and Happell, 2011). Well-designed trials are required, including further high-quality 
qualitative research. The trials should also involve fundamental investigations into, for example, the effect of interventions on physical health. There is no acceptable reason for the health care system to accept poorer physical health in patients with psychosis than in the general population.

\section{Conclusion}

The study shows that patients suffering from psychosis have significantly lower HRQoL regarding all components in EQ5D, except for the pain/discomfort component, in comparison with the reference sample. According to the IDF (2009) definition, almost half of the patient group met the criteria for metabolic syndrome. The only risk factor included in the metabolic syndrome that was associated with HRQoL was elevated blood pressure. Raised LDLcholesterol was also related to lower HRQoL, together with low GAF, older age, high BMI and female gender. The overall situation is problematic as these patients are at great additional risks for physical comorbidity. 


\section{References}

Alberti, K.G., Eckel, R.H., Grundy, S.M., Zimmet, P.Z., Cleeman, J.I., Donato, K.A., Fruchart, J.C., James, W.P., Loria, C.M., Smith, S.C., Jr., International Diabetes Federation Task Force on, E., Prevention, Hational Heart, L., Blood, I., American Heart, A., World Heart, F., International Atherosclerosis, S., International Association for the Study of, O., 2009. Harmonizing the metabolic syndrome: a joint interim statement of the International Diabetes Federation Task Force on Epidemiology and Prevention; National Heart, Lung, and Blood Institute; American Heart Association; World Heart Federation; International Atherosclerosis Society; and International Association for the Study of Obesity. Circulation 120(16), 1640-1645.

Bobes, J., Arango, C., Garcia-Garcia, M., Rejas, J., 2010. Healthy lifestyle habits and 10-year cardiovascular risk in schizophrenia spectrum disorders: an analysis of the impact of smoking tobacco in the CLAMORS schizophrenia cohort. Schizophrenia research 119(1-3), 101-109.

Bobes, J., Garcia-Portilla, P., Saiz, P.A., Bascaran, T., Bousono, M., 2005. Quality of life measures in schizophrenia. European psychiatry : the journal of the Association of European Psychiatrists 20 Suppl 3, S313-317.

Brooks, R., 1996. EuroQol: the current state of play. Health policy 37(1), 53-72.

Burstrom, K., Johannesson, M., Diderichsen, F., 2001. Health-related quality of life by disease and socio-economic group in the general population in Sweden. Health policy 55(1), 51-69.

Caron, J., Lecomte, Y., Stip, E., Renaud, S., 2005. Predictors of quality of life in schizophrenia. Community mental health journal 41(4), 399-417.

Carpiniello, B., Pinna, F., Tusconi, M., Zaccheddu, E., Fatteri, F., 2012. Gender differences in remission and recovery of schizophrenic and schizoaffective patients: preliminary results of a prospective cohort study. Schizophrenia research and treatment 2012, 576369.

Cramer, J.A., Rosenheck, R., Xu, W., Thomas, J., Henderson, W., Charney, D.S., 2000. Quality of life in schizophrenia: a comparison of instruments. Department of Veterans Affairs Cooperative Study Group on Clozapine in Refractory Schizophrenia. Schizophrenia bulletin 26(3), 659666.

Cruce, G., Ojehagen, A., 2007. Risky use of alcohol, drugs and cigarettes in a psychosis unit: a 1 1/2 year follow-up of stability and changes after initial screening. BMC psychiatry 7,31 .

Crump, C., Winkleby, M.A., Sundquist, K., Sundquist, J., 2013. Comorbidities and mortality in persons with schizophrenia: a Swedish national cohort study. The American journal of psychiatry 170(3), 324-333.

de Miguel Diez, J., Esteban y Pena, M.M., Puente Maestu, L., Hernandez Barrera, V., Carrasco Garrido, P., Alvarez-Sala Walther, L.A., Jimenez Garcia, R., 2010. Relationship between tobacco consumption and health-related quality of life in adults living in a large metropolitan area. Lung 188(5), 393-399.

Despres, J.P., Arsenault, B.J., Cote, M., Cartier, A., Lemieux, I., 2008. Abdominal obesity: the cholesterol of the 21st century? The Canadian journal of cardiology 24 Suppl D, 7D-12D.

Dipasquale, S., Pariante, C.M., Dazzan, P., Aguglia, E., McGuire, P., Mondelli, V., 2013. The dietary pattern of patients with schizophrenia: a systematic review. Journal of psychiatric research 47(2), 197-207.

Dolan, P., 1997. Modeling valuations for EuroQol health states. Medical care 35(11), 1095-1108.

Faulkner, G., Cohn, T., Remington, G., 2007. Interventions to reduce weight gain in schizophrenia. Schizophrenia bulletin 33(3), 654-656.

Foley, D.L., Morley, K.I., 2011. Systematic review of early cardiometabolic outcomes of the first treated episode of psychosis. Archives of general psychiatry 68(6), 609-616.

Fountoulakis, K.N., Siamouli, M., Panagiotidis, P., Magiria, S., Kantartzis, S., Papastergiou, N., Shoretsanitis, G., Pantoula, E., Moutou, K., Kouidi, E., Deres, S., 2010. Obesity and smoking in 
patients with schizophrenia and normal controls: a case-control study. Psychiatry research 176(1), 13-16.

Frisman, G.H., Kristenson, M., 2009. Psychosocial status and health related quality of life in relation to the metabolic syndrome in a Swedish middle-aged population. European journal of cardiovascular nursing : journal of the Working Group on Cardiovascular Nursing of the European Society of Cardiology 8(3), 207-215.

Guy, W., Cleary, P., Bonato, R.R., 1970. The chronic schizophrenic as a research subject: Toxicity measures and their relationship to efficacy measures. Psychopharmacology bulletin 6(4), 3458.

Heider, D., Kitze, K., Zieger, M., Riedel-Heller, S.G., Angermeyer, M.C., 2007. Health-related quality of life in patients after lumbar disc surgery: a longitudinal observational study. Quality of life research : an international journal of quality of life aspects of treatment, care and rehabilitation 16(9), 1453-1460.

Hultsjo, S., 2012. Mental healthcare staff's knowledge and experiences of diabetes care for persons with psychosis - a qualitative interview study. Primary health care research \& development, $1-12$.

Kind, P., Dolan, P., Gudex, C., Williams, A., 1998. Variations in population health status: results from a United Kingdom national questionnaire survey. Bmj 316(7133), 736-741.

Klop, B., Elte, J.W., Cabezas, M.C., 2013. Dyslipidemia in obesity: mechanisms and potential targets. Nutrients 5(4), 1218-1240.

Konig, H.H., Roick, C., Angermeyer, M.C., 2007. Validity of the EQ-5D in assessing and valuing health status in patients with schizophrenic, schizotypal or delusional disorders. European psychiatry : the journal of the Association of European Psychiatrists 22(3), 177-187.

Laursen, T.M., Munk-Olsen, T., Vestergaard, M., 2012. Life expectancy and cardiovascular mortality in persons with schizophrenia. Current opinion in psychiatry 25(2), 83-88.

Marder, S.R., Fenton, W., Youens, K., 2004. Schizophrenia, IX: Cognition in schizophrenia--the MATRICS initiative. The American journal of psychiatry 161(1), 25.

McEvoy, J.P., Zigman, D., Margolese, H.C., 2010. First- and second-generation antipsychotics. Canadian journal of psychiatry. Revue canadienne de psychiatrie 55(3), 144-148; discussion 148-149.

Mercier, C., Peladeau, N., Tempier, R., 1998. Age, gender and quality of life. Community mental health journal 34(5), 487-500.

Meyer, J.M., Stahl, S.M., 2009. The metabolic syndrome and schizophrenia. Acta psychiatrica Scandinavica 119(1), 4-14.

Newcomer, J.W., 2005. Second-generation (atypical) antipsychotics and metabolic effects: a comprehensive literature review. CNS drugs 19 Suppl 1, 1-93.

Renzaho, A., Wooden, M., Houng, B., 2010. Associations between body mass index and healthrelated quality of life among Australian adults. Quality of life research : an international journal of quality of life aspects of treatment, care and rehabilitation 19(4), 515-520.

Resnick, B., Orwig, D., Wehren, L., Hawkes, W., Hebel, R., Zimmerman, S., Magaziner, J., 2005. Health-related quality of life: is it a good indicator of function post THR? Rehabilitation nursing : the official journal of the Association of Rehabilitation Nurses 30(2), 46-54, 67.

Ritsner, M., Modai, I., Endicott, J., Rivkin, O., Nechamkin, Y., Barak, P., Goldin, V., Ponizovsky, A., 2000. Differences in quality of life domains and psychopathologic and psychosocial factors in psychiatric patients. The Journal of clinical psychiatry 61(11), 880-889; quiz 890.

Roohafza, H., Sadeghi, M., Talaei, M., Pourmoghaddas, Z., Sarrafzadegan, N., 2012. Psychological status and quality of life in relation to the metabolic syndrome: Isfahan Cohort Study. International journal of endocrinology 2012, 380902.

Ruggeri, M., Nose, M., Bonetto, C., Cristofalo, D., Lasalvia, A., Salvi, G., Stefani, B., Malchiodi, F., Tansella, M., 2005. Changes and predictors of change in objective and subjective quality of 
life: multiwave follow-up study in community psychiatric practice. The British journal of psychiatry : the journal of mental science 187, 121-130.

Scott, D., Happell, B., 2011. The high prevalence of poor physical health and unhealthy lifestyle behaviours in individuals with severe mental illness. Issues in mental health nursing 32(9), 589-597.

Skantze, K., 1998. Subjective quality of life and standard of living: a 10-year follow-up of out-patients with schizophrenia. Acta psychiatrica Scandinavica 98(5), 390-399.

Strassnig, M., Brar, J.S., Ganguli, R., 2003. Body mass index and quality of life in community-dwelling patients with schizophrenia. Schizophrenia research 62(1-2), 73-76.

Strine, T.W., Okoro, C.A., Chapman, D.P., Balluz, L.S., Ford, E.S., Ajani, U.A., Mokdad, A.H., 2005. Health-related quality of life and health risk behaviors among smokers. American journal of preventive medicine 28(2), 182-187.

Trevisol, D.J., Moreira, L.B., Kerkhoff, A., Fuchs, S.C., Fuchs, F.D., 2011. Health-related quality of life and hypertension: a systematic review and meta-analysis of observational studies. Journal of hypertension 29(2), 179-188.

Zygmuntowicz, M., Owczarek, A., Elibol, A., Olszanecka-Glinianowicz, M., Chudek, J., 2013. Blood pressure for optimal health-related quality of life in hypertensive patients. Journal of hypertension 31(4), 830-839. 
Table 1. Demographic and clinical characteristics in patients with psychosis $(n=903)$ and a population based reference group $(n=7,238)$.

\begin{tabular}{|c|c|c|c|c|c|c|}
\hline \multirow[b]{2}{*}{ Variable } & \multicolumn{3}{|c|}{ Patients } & \multicolumn{2}{|c|}{ Reference group } & \multirow[b]{2}{*}{$\mathrm{p}$} \\
\hline & & $\mathrm{n}$ & $(\%)$ & $\mathrm{n}$ & $(\%)$ & \\
\hline Male & & 497 & 55.0 & 3289 & 45.4 & $<0.001$ \\
\hline \multirow[t]{2}{*}{ Age } & Mean & 47.2 & - & 51.2 & - & $<0.001$ \\
\hline & Range & $21-84$ & - & $18-84$ & - & \\
\hline \multicolumn{7}{|l|}{ Smoking } \\
\hline & Smoker & 378 & 42.2 & 1392 & 19.4 & $<0.001$ \\
\hline & Non-smoker & 518 & 57.8 & 5767 & 80.6 & \\
\hline & Missing & 7 & - & 79 & - & \\
\hline \multicolumn{7}{|c|}{ Alcohol, g per week } \\
\hline & 0 & 370 & 41.2 & 1353 & 19.3 & $<0.001$ \\
\hline & $1-199$ & 421 & 46.9 & 5485 & 78.2 & \\
\hline & $\geq 200$ & 106 & 11.8 & 176 & 2.5 & \\
\hline & Missing & 6 & - & 224 & - & \\
\hline \multicolumn{7}{|c|}{ Body Mass Index } \\
\hline & $\leq 25$ & 256 & 28.8 & 3884 & 56.5 & $<0.001$ \\
\hline & $26-30$ & 333 & 37.5 & 2246 & 32.6 & \\
\hline & $31-35$ & 182 & 20.5 & 567 & 8.2 & \\
\hline & $>35$ & 117 & 13.2 & 183 & 2.7 & \\
\hline & Missing & 15 & - & 358 & & \\
\hline \multicolumn{7}{|l|}{ EQ5D } \\
\hline \multirow{2}{*}{$\begin{array}{l}\text { index } \\
\text { SD }\end{array}$} & M & 0.727 & & 0.812 & & $\mathrm{p}<0.001$ \\
\hline & $\mathrm{SD}$ & 0.207 & & 0.253 & & \\
\hline \multicolumn{2}{|c|}{ mobility, no problems } & 748 & 82.8 & 6176 & 85.9 & $\mathrm{p}=0.012$ \\
\hline \multicolumn{2}{|c|}{ hygiene, no problems } & 856 & 94.8 & 7021 & 97.6 & $\mathrm{p}<0.001$ \\
\hline \multicolumn{2}{|c|}{ main activities, no problems } & 647 & 71.7 & 6741 & 90.0 & $\mathrm{p}<0.001$ \\
\hline \multicolumn{2}{|c|}{ pain/discomfort, no problems } & 495 & 54.8 & 3265 & 45.5 & $\mathrm{p}<0.001$ \\
\hline \multicolumn{2}{|c|}{ worry/sadness, no problems } & 312 & 34.6 & 4742 & 66.0 & $\mathrm{p}<0.001$ \\
\hline
\end{tabular}

$\mathrm{M}=$ Mean

$\mathrm{SD}=$ Standard Deviation 
Table 2. Clinical characteristics of the patients with psychosis $(n=903)$.

\begin{tabular}{|c|c|c|c|c|c|c|}
\hline Variable & $\mathrm{n}$ & $(\%)$ & Mean & Median & $\mathrm{SD}$ & IQR \\
\hline \multicolumn{7}{|l|}{ Diagnosis } \\
\hline Schizophrenia & 480 & 62 & & & & \\
\hline Schizoaffective disorder & 116 & 11 & & & & \\
\hline Delusional disorder & 86 & 7 & & & & \\
\hline Psychosis NOS & 138 & 14 & & & & \\
\hline Bipolar disorder & 83 & 6 & & & & \\
\hline Antipsychotic treatment in years & & & & 16.0 & & 18.0 \\
\hline Number of hospitalizations & & & & 3.0 & & 5.0 \\
\hline Months in hospital & & & & 4.0 & & 11.0 \\
\hline 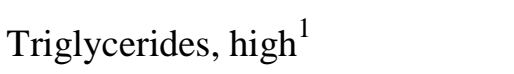 & 325 & 36 & 1.5 & 1.4 & 0.8 & 1.1 \\
\hline HDL cholesterol low ${ }^{1}$ & 360 & 40 & 1.2 & 1.1 & 0.4 & 0.4 \\
\hline LDL, cholesterol high $^{1}$ & 418 & 46 & 3.5 & 3.4 & 1.0 & 1.2 \\
\hline Glucose fasting high ${ }^{1}$ & 554 & 61 & 5.6 & 5.3 & 1.4 & 1.0 \\
\hline Blood pressure increased ${ }^{1}$ & 531 & 59 & $\mathrm{n}$ & $\mathrm{n}$ & $\mathrm{n}$ & $\mathrm{n}$ \\
\hline Waist circumference $^{1}$ & 571 & 63 & $\mathrm{n}$ & $\mathrm{n}$ & $\mathrm{n}$ & $\mathrm{n}$ \\
\hline
\end{tabular}

$\mathrm{IQR}=$ Interquartile range

${ }^{1}$ according to IDF criteria 
Table 3. Variables significantly related to a higher EQ5D index of the patients with psychosis ( $n=$ 738) in a logistic regression analysis (stepwise forward).

\begin{tabular}{lcccccc}
\hline & & & & & \multicolumn{2}{c}{$95 \%$ C.I.for OR } \\
\cline { 6 - 8 } Variable & $\mathrm{b}$ & $\mathrm{SE}$ & $\mathrm{p}$ & $\mathrm{OR}^{1}$ & Lower & Higher \\
\hline Blood pressure & -0.37 & 0.161 & 0.020 & $0.69^{2}$ & 0.50 & 0.94 \\
Age $>$ 44 year & -0.37 & 0.161 & 0.022 & $0.69^{2}$ & 0.51 & 0.95 \\
CGI & -0.36 & 0.46 & 0.039 & 0.70 & 0.49 & 0.98 \\
GAF & 0.35 & 0.175 & 0.044 & 1.42 & 1.01 & 2.01 \\
Gender & -0.35 & 0.156 & 0.027 & $0.70^{2}$ & 0.52 & 0.96 \\
LDL-cholesterol & -0.34 & 0.155 & 0.031 & $0.72^{2}$ & 0.53 & 0.97 \\
Constant & 1.15 & 0.343 & & & & \\
\hline
\end{tabular}

${ }^{1}$ The ORs are ranked according to their magnitude.

${ }^{2}$ ORs below 1.00 are inverted before ranking. 